\title{
Placental fibroblast growth factor 21 is not altered in late-onset preeclampsia
}

\author{
Marloes Dekker Nitert ${ }^{1,2 *}$, Katherin Scholz-Romero², Marta H Kubala², H David Mclntyre ${ }^{1,4}$, Leonie K Callaway ${ }^{1,2,3}$ \\ and Helen L Barrett ${ }^{1,2,3}$
}

\begin{abstract}
Background: Preeclampsia (PE) is associated with alterations of placental function. The incidence of PE is higher in insulin resistant states. Women with PE have high circulating levels of the metabolic regulator fibroblast growth factor 21 (FGF21). FGF21 is synthesized in the placenta. The aim of this study was to compare the expression of FGF21, its receptors, downstream targets and transcriptional regulators in placental tissue from pregnancies with and without late-onset PE. Circulating FGF21 in maternal and cord blood was also studied.

Methods: mRNA expression was determined by semi-quantitative real-time PCR and normalized for cellular composition in 17 women with and 20 without PE. Protein expression was quantified by Western Blot. FGF21 levels were measured by ELISA in maternal and cord serum of ten mother-baby dyads per condition.

Results: Placental FGF21 mRNA and protein expression were similar in PE compared with control. Placental mRNA expression of the FGF receptors (1-4) and the co-receptor beta-Klotho was not different between the groups. There was no difference in the expression of the glucose transporters GLUT1, 3 or 4. PPAR-alpha but not PPAR-gamma expression was decreased in PE. Maternal FGF21 serum levels were not significantly different in PE. FGF21 was detected in cord blood of 6 infants (4 PE, 2 controls) but was undetectable in 14 infants.
\end{abstract}

Conclusions: Late-onset PE is not associated with major changes to the expression of FGF21, its receptors or metabolic targets.

Keywords: FGF21, Preeclampsia, Placenta, PPAR-alpha, PPAR-gamma, GLUT

\section{Background}

Preeclampsia (PE), a syndrome of hypertension and proteinuria, is a common complication of pregnancy affecting 2 to $8 \%$ of pregnancies worldwide [1]. The diagnostic criteria include hypertension with blood pressures $>140 /$ $90 \mathrm{mmHg}$ and proteinuria developing after 20 weeks gestation. PE (in particular early-onset PE diagnosed prior to 34 weeks gestation) is associated with adverse outcomes for mother and baby including preterm delivery, stillbirth and intrauterine growth restriction. In the long term, women with PE complicating their pregnancy have higher risks of developing hypertension, cardiovascular disease and type 2 diabetes $[2,3]$.

\footnotetext{
*Correspondence: m.dekker@uq.edu.au

${ }^{1}$ School of Medicine, The University of Queensland, Butterfield Street,

Herston 4029, QLD, Australia

${ }^{2}$ The University of Queensland Centre for Clinical Research, The University of Queensland, Herston, QLD, Australia

Full list of author information is available at the end of the article
}

The risk of developing PE is higher in women with increased insulin resistance, as occurs in obesity and gestational diabetes mellitus [4]. Recently, there has been significant interest in a newly discovered metabolic regulator, fibroblast growth factor 21 (FGF21). FGF21 increases insulin sensitivity, glucose and lipid metabolism [5-8]. FGF21 is synthesized and secreted from the liver, adipose tissue, pancreatic $\beta$-cells, skeletal muscle, white blood cells and possibly cerebrospinal fluid [9-12]. Recent reports have shown that circulating levels of FGF21 at 28 weeks gestation are increased in women with $\mathrm{PE}$ compared with controls [13]. This suggests that FGF21 might have a role in the regulation of metabolism, and provide some explanation of the link between insulin resistance and PE.

We have previously shown that FGF21 is synthesized in the placenta [14]. The placenta not only transfers nutrients but also actively synthesizes and secretes a large 
number of molecules, such as FGF21. It could be useful to understand the role of these molecules in pregnancy pathology. FGF21 can bind to all four isoforms of the FGF-receptor (FGFR), although preferentially to FGFR1. The co-receptor $\beta$-klotho increases binding affinity between FGF21 and its receptor [15]. Human placenta expresses all four FGF receptor isoforms in addition to $\beta$-klotho [14]. In placenta, FGF21 mRNA expression is positively correlated with increased expression of glucose transporters (GLUT) [14]. Transcriptional regulation of FGF21 is under the control of peroxisome proliferator-activated receptors (PPARs) $\alpha$ and $\gamma[16,17]$. In the placentae of women with an uncomplicated pregnancy or gestational diabetes mellitus, there was a positive correlation between the gene expression levels of PPAR $\alpha$ and FGF21 and a tendency for a positive correlation between PPAR $\gamma$ and FGF21 [14].

Since the placenta synthesizes FGF21, it has been hypothesized that it could be involved in the regulation of placental metabolism, which may affect infant growth and development through differential expression of nutrient receptors and transporters. Given the relationship between insulin resistance and PE, the role FGF21 plays may be critical. To date, it is not clear whether placental FGF21 is differentially expressed in preeclampsia and if this could contribute to altered placental metabolism.

This study investigated whether expression of placental FGF21, its receptors and co-receptor as well as its transcriptional regulators and metabolic targets differed in preeclampsia as compared to normal pregnancy. Circulating FGF21 in maternal blood and infant cord serum was also measured in mother-baby dyads to assess if $\mathrm{PE}$ affects these levels.

\section{Methods}

\section{Participants}

Pregnant women were enrolled with informed consent in the third trimester of pregnancy, with approval from the human research ethics committees from the Royal Brisbane and Women's Hospital and The University of Queensland. Seventeen women were diagnosed with preeclampsia according to the SOMANZ research criteria from 2008, consisting of two blood pressure measurements of $>140 / 90$ separated by $>2$ hours and the presence of proteinuria [18]. A control group of 20 normotensive women was selected with matching for pre-pregnancy BMI, gestational age at delivery, baby gender, birth weight and maternal age. Women with diabetes were excluded from this study. Placental samples and cord blood samples were collected at delivery. One $\mathrm{cm}^{3}$ samples were taken from the maternal and fetal sides of the placenta in areas away from calcifications and visible anatomical abnormalities, snap-frozen in liquid nitrogen and stored at $-80^{\circ} \mathrm{C}$. Cord blood was spun for 10 minutes at room temperature at $3000 \mathrm{xg}$, serum was collected and stored at $-80^{\circ} \mathrm{C}$ until use. For immunohistochemistry, $1 \mathrm{~cm}^{3}$ samples were obtained from both sides of the placenta, washed in PBS, preserved in $4 \%$ paraformaldehyde for 72 hours until transfer to saturated sucrose until paraffin embedding.

\section{Gene expression analysis}

Total RNA was isolated from the frozen placental samples with the DNA/RNA AllPrep kit (Qiagen) according to the manufacturer's instructions. The samples were lysed in lysis buffer through agitation with a $5 \mathrm{~mm}$ stainless steel ball for $2 \times 2$ minutes at $30 \mathrm{~Hz}$ in the TissueLyser II (Qiagen). 750 ng of total RNA 260/280 ratios > 1.8 was transcribed to cDNA with the QuantiTect Reverse Transcription kit (Qiagen) employing a mixture of random hexamers and oligodT primers according to the manufacturer's recommendations.

Primers were designed for each target gene with the NCBI primer design tool, ensuring coverage of an exonexon junction in one of the primers of the primer pair. All primer sequences and products were blasted and were specific for the target gene only. The primer sequences and amplicon lengths are listed in Additional file 1: Table S1.

$18.75 \mathrm{ng}$ of cDNA, $300 \mathrm{nM}$ of forward and reverse primer and $10 \mu \mathrm{l}$ iTaq universal SYBR green PCR master mix (BioRad) was used per QPCR reaction in a iQ5 QPCR machine (BioRad). Cycling conditions consisted on 1 cycle at $95^{\circ} \mathrm{C}$ for $10 \mathrm{~min}, 40$ cycles of 15 seconds at $95^{\circ} \mathrm{C}$ and 1 minute at $59^{\circ} \mathrm{C}$, followed by melt curve analysis.

Target gene expression was normalized to the geometric mean of the expression of the endogenous control gene $T B P$, and the expression of the cellular markers CK7 (trophoblasts), CD34 (endothelial cells), and DES (smooth muscle cells) to adjust for potential differences in cellular composition of the placental samples. Target gene expression was analyzed with the $\Delta \Delta \mathrm{Ct}$ method after ensuring amplication efficiency varied between 90 and $110 \%$.

\section{Protein expression analysis}

Protein was isolated from placental samples by agitation with a $5 \mathrm{~mm}$ stainless steel ball in RIPA buffer for $2 \times 2$ minutes at $30 \mathrm{~Hz}$ in the TissueLyserII. Supernatant was obtained, spun for $10 \mathrm{~min}$ at $4^{\circ} \mathrm{C}$ at $12000 \mathrm{rpm}$ to remove cellular debris. Protein content was measured with the BCA method.

Thirty $\mu$ g of protein was loaded onto a 4-12\% NuPAGE ${ }^{\circ}$ BIs-Tris gel (Life Technologies, Mulgrave, VIC, Australia), run and transferred to a polyvinylidene difluoride membrane (Millipore, Kilsythe, VIC, Australia). Non-specific binding of antibodies was blocked by preincubating the 
membranes for 60 minutes in 5\% non-fat dry milk dissolved in TBS-Tween. The blots were incubated overnight at $4^{\circ} \mathrm{C}$ with the primary antibodies, washed and incubated for 1 hour at room temperature with the secondary antibodies. The LI-COR system was used enabling simultaneous visualization of the target protein and the loading control ( $\beta$-actin). Densitometric analysis was performed with the Odyssey Infrared Imaging system.

Primary polyclonal rabbit anti-human FGF21 (ab64857, Abcam, Cambridge MA, USA) was diluted to $1 \mu \mathrm{g} / \mathrm{ml}$ and mouse monoclonal anti-human $\beta$-actin (A5316, Sigma Aldrich, Castle Hill, NSW Australia) was diluted 1:20000 in $5 \%$ non-fat dry milk/PBS-Tween. Secondary LiCOR antibodies were diluted at 1:10000 for goat anti-rabbit 800CW (926-32211, LI-COR) and at 1:15000 for donkey anti-mouse 680LT (926-68022, LI-COR).

\section{Protein localization}

Immunohistochemistry was used to localize FGF21 expression to the placenta. Five $\mu \mathrm{m}$ thick sections of paraffin-embedded placental samples $(\mathrm{N}=4$ for $\mathrm{PE}$ and controls each) were baked and dehydrated. Antigen retrieval was performed by incubation of the samples in citrate buffer (10 mM, pH6.0) for 30 minutes. Endogenous hydrogen peroxidase activity was blocked by incubating the slides for $10 \mathrm{~min}$ with $3 \%$ hydrogen peroxide followed by $15 \mathrm{~min}$ with the universal non-specific background-blocking agent Biocare Background Sniper (MACH2, Biocare Medical, Concord CA, USA). The slides were incubated overnight with primary antibody, human rabbit anti-human FGF21 (ab54857, Abcam) at 1:300 at $4^{\circ} \mathrm{C}$. The slides were washed and incubated with rabbit HRP-polymer (MACH2, Biocare Medical) for 60 minutes at room temperature. HRP activity was visualized by $\mathrm{DAB}$ and the slides were counterstained with Harris' Haematoxylin (HHS16, Sigma Aldrich) and mounted with coverslips. To ensure antibody specificity, staining was performed in the absence of primary antibody or in the presence of IgG control as primary antibody yielding similar patterns of background staining.

\section{Circulating FGF21 levels}

Maternal and cord blood serum samples of 10 motherbaby dyads were analyzed in duplicate for human FGF21 by ELISA (ab125966, Abcam) following the manufacturer's recommendations. The detection limit of this assay is $0.03 \mathrm{ng} / \mathrm{mL}$, the intra-assay variability is $4.8 \%$ and the inter-assay variability is $7.4 \%$.

\section{Statistical analysis}

The participant characteristics, which are normally distributed as tested by the D'Agostino \& Pearson omnibus normality test, are reported as means $\pm S D$ and compared with Student's $t$-tests. The experimental data were tested for adherence to the normal distribution and did not conform. These data were therefore reported as median (interquartile range IQR) and all statistical analyses were performed with non-parametric methods: A Kruskal-Wallis one-way analysis of variance by ranks test for the comparisons between groups and Spearman's rank correlation tests for correlations. Dunn's multiple comparisons test was applied to correct for multiple testing where necessary.

\section{Results}

\section{Study population}

Seventeen women with and 20 women without PE were recruited for this study. The women were matched for gestational age of delivery, maternal age, pre-pregnancy BMI and gender of the baby (Table 1). The women with PE had significantly higher systolic and diastolic blood pressure at enrolment in the study, even with 11 women on treatment with anti-hypertensive agents. The women with PE also had a tendency for higher systolic blood pressure in early pregnancy $(115+/-14$ vs. $107+/-8 \mathrm{mmHg}$, $P=0.08$ for normotensive women). Maternal blood glucose values in response to a $50 \mathrm{~g}$ glucose challenge test were similar in both groups and none of the women were diagnosed with gestational diabetes mellitus.

\section{FGF21 expression in preeclampsia}

Placental FGF21 mRNA expression was not significantly increased in women with PE (PE median 1.96 (IQR 0.11-7.60) vs. controls $0.14(0.03-2.37), P=0.24)$ (Figure 1A). Protein

Table 1 Clinical characteristics of the study participants

\begin{tabular}{llll}
\hline & Control & PE & P-value \\
\hline $\mathrm{N}$ & 20 & 17 & \\
Age (years) & $32.8 \pm 5.3$ & $30.2 \pm 6.7$ & 0.25 \\
Pre-pregnancy BMI (kg/m2) & $24.9 \pm 4.9$ & $25.2 \pm 5.5$ & 0.87 \\
Gravidity (median, IQR) & $2.5(2-4)$ & $2(1-4)$ & $\mathrm{ND}$ \\
Parity (median, IQR) & $1(1-2)$ & $0(0-1)$ & $\mathrm{ND}$ \\
Ethniticy (Caucasian/other) & $18 / 2$ & $17 / 0$ & $\mathrm{ND}$ \\
SBP (T3) mmHg & $118 \pm 13$ & $135 \pm 18^{*}$ & 0.003 \\
DBP (T3) mmHg & $73 \pm 9$ & $84 \pm 15^{*}$ & 0.01 \\
SBP (early preg) mmHg & $107 \pm 8$ & $115 \pm 14$ & 0.08 \\
DBP (early preg) mmHg & $65 \pm 8$ & $67 \pm 10$ & 0.40 \\
Mode of delivery (VD/CS) & $0 / 20$ & $10 / 7$ & $<0.0001$ \\
GA delivery (d) & $269.6 \pm 8.3$ & $268.1 \pm 10.3$ & 0.64 \\
Birth weight (g) & $3279 \pm 623$ & $3150 \pm 673$ & 0.55 \\
Baby gender (M/F) & $10 / 10$ & $9 / 8$ & $\mathrm{ND}$ \\
Glucose screen result (mmol/L) & $5.76 \pm 1.02$ & $6.10 \pm 1.46$ & 0.51 \\
\hline
\end{tabular}

Results expressed as mean \pm SD unless indicated otherwise; ND, not determined; VD, vaginal delivery; CS, Caesarean section; *11 of the 17 treated with anti-hypertensive agents. 


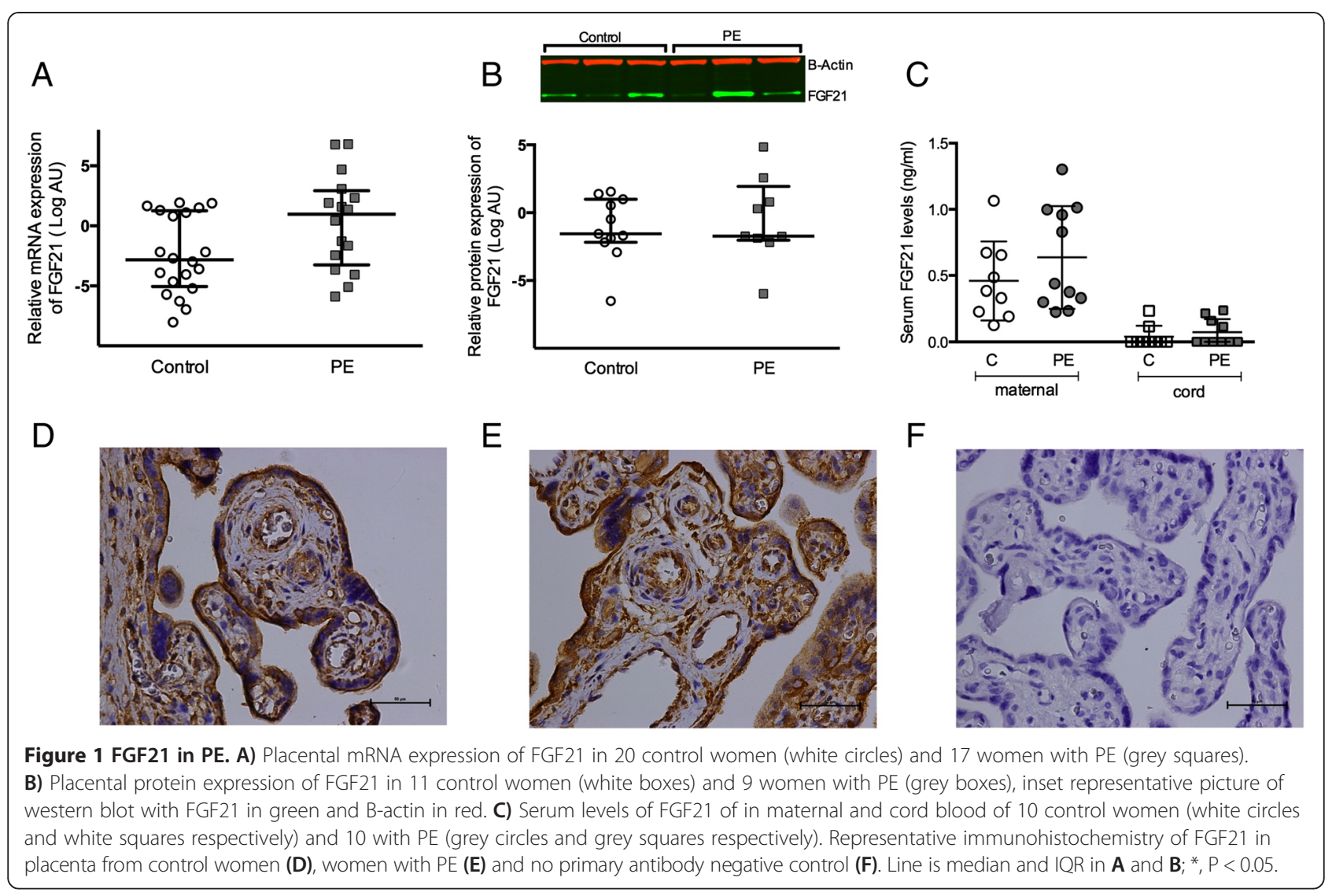

levels for FGF21 were not significantly altered in PE (PE $0.30(0.25-3.85)$ vs. controls $0.34(0.22-1.99), P=0.87)$ (Figure 1B). The inter-individual variation in gene and protein expression of FGF21 was extensive but was not correlated to maternal factors such as pre-pregnancy BMI, gestational age at delivery or birth weight. FGF21 protein was localized to trophoblasts, endothelial cells, stromal cells (Figure 1D and E) and decidual cells (Additional file 2: Figure S1). There was no apparent difference in the protein localization or amount between placental tissue from women with or without PE.

Circulating FGF21 was examined in maternal and cord blood samples of 10 mother-baby dyads in each group. FGF21 levels in maternal blood were similar in women with and without PE (PE 0.44 (0.30-1.00) ng/ml vs. control 0.38 (0.21-0.66), $P=0.38$ ) (Figure 1C). Maternal FGF21 levels were correlated to maternal systolic blood pressure at enrolment (rho $0.50, P=0.02$ ) but not to diastolic blood pressure (rho 0.39, $P=0.09$ ) or prepregnancy BMI (rho $-0.04, P=0.87$ ). Cord blood FGF21 fell below the level of detection $(0.03 \mathrm{ng} / \mathrm{ml})$ in most cord blood samples but was just above the level of detection in 2 cord blood samples of normotensive pregnancies and 4 cord blood samples of PE pregnancies. Cord blood FGF21 levels were not correlated to maternal FGF21 levels.

\section{FGF receptors}

FGF21 can bind to all four isoforms of the FGF receptor family with a preference for FGFR4 especially in the presence of the co-receptor $\beta$-klotho $(K L B)$. In PE, placental expression of each of the FGFR isoforms was not different from control pregnancies (Figure 2A): FGFR1 mRNA expression in PE 0.45 (0.14-2.33) vs. control 0.56 (0.15-1.30), $P=0.99$; FGFR2 PE $0.36(0.15-3.21)$ vs. control 0.59 (0.22-1.52), $P=0.99$; FGFR3 PE 0.48 (0.11-1.56) vs. control 0.61 (0.27-1.59), $P=0.99$; and FGFR4 PE 0.19 (0.07-0.79) vs. control 0.58 (0.16-1.68), $P=0.99$. Placental mRNA expression for the co-factor $\beta$-klotho was not significantly increased in PE (1.07 (0.28-15.31)) vs. control $0.26(0.10-1.09), P=0.13$. However, FGF21 mRNA expression correlated significantly and positively with the expression of all FGFR isoforms (Figure 2B-E) as well as $\beta$-klotho (Figure 2F).

\section{PPAR mRNA expression in preeclampsia}

FGF21 mRNA expression is regulated by PPAR $\alpha$ and $\gamma$ in different tissues. Placental mRNA expression of PPAR $\alpha$ and $\gamma$ was investigated in our cohort of PE women. PPAR $\alpha$ expression in the placenta was significantly decreased in PE (0.12 (0.09-0.59)) compared with controls (0.73 (0.39$1.57)), P=0.049$. Placental PPAR $\gamma$ mRNA expression was 


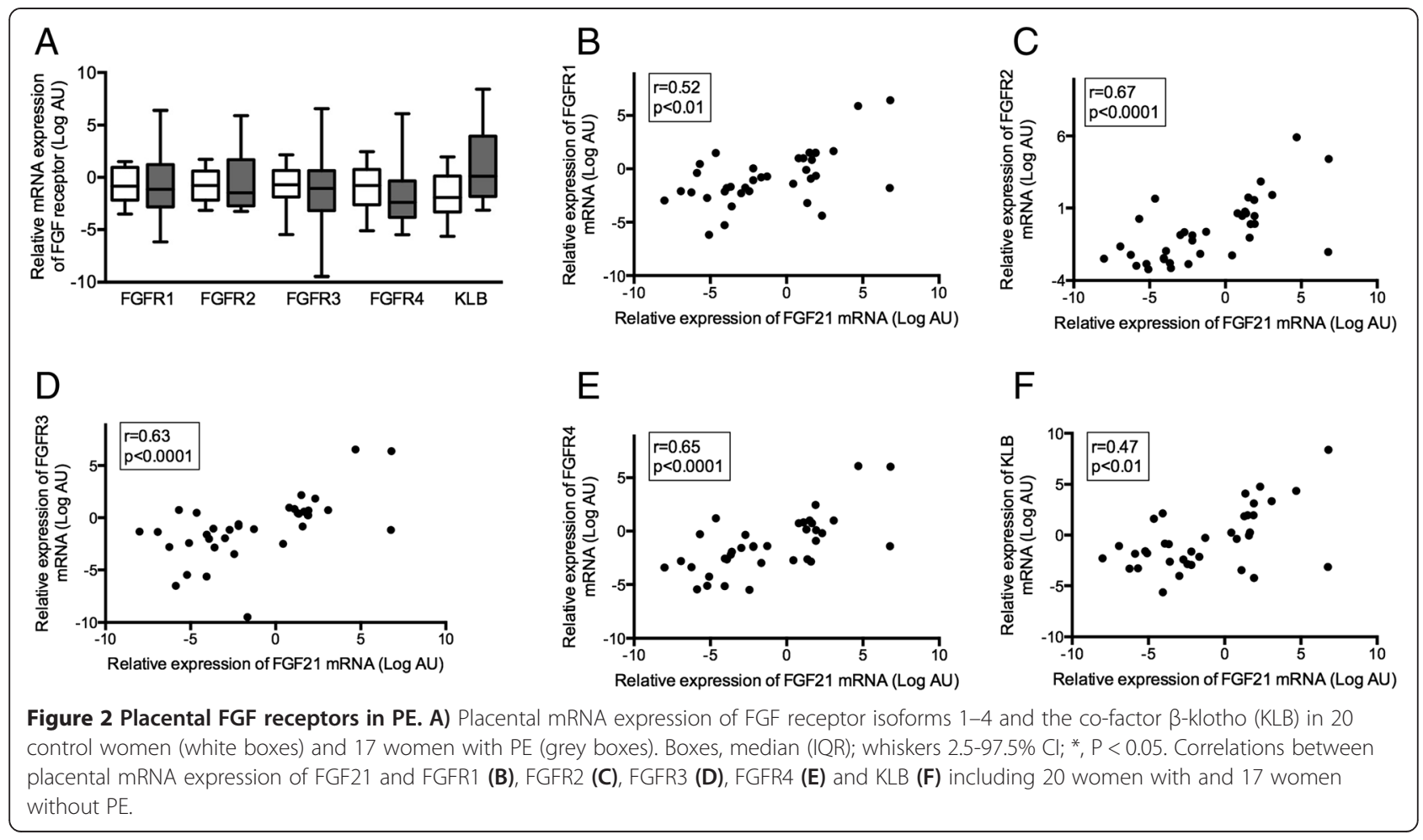

not different between women with $(0.27(0.16-0.57))$ or without PE (0.59 (0.15-1.30)), $P=0.99$ (Figure 3A). FGF21 mRNA expression was however positively correlated to PPAR $\gamma$ mRNA expression (Spearman's $\rho=0.62$, $P<0.0001$ ) (Figure $3 B$ ) but not to PPAR $\alpha$ mRNA expression (Spearman's $\rho=-0.09, P=0.62$ ).

\section{Glucose transporter mRNA expression in preeclampsia}

Glucose transporters are targets of FGF21 signaling. We analyzed the gene expression of the glucose transporters GLUT1, GLUT3 and GLUT4 in the placentas from women with and without PE. There were no significant differences in the expression of the GLUTs between the groups (Figure 3C). The expression levels of FGF21
mRNA were positively correlated with those of GLUT1 (Spearman's $\rho=0.50, P=0.0019$ ), GLUT3 (Spearman's $P=0.74, P<0.0001$ ) and GLUT4 (Spearman's $\rho=0.58$, $P=0.0002)$.

\section{Discussion}

The aim of the current study was to investigate whether FGF21, its receptors and transcriptional activators and downstream targets in the placenta were altered in the setting of PE. No changes were seen in placental FGF21 mRNA levels, its protein level, localization and expression of its receptors, co-receptor or downstream targets GLUT1, 3, and 4 was not changed. PE was however associated with decreased placental expression of PPAR $\alpha$

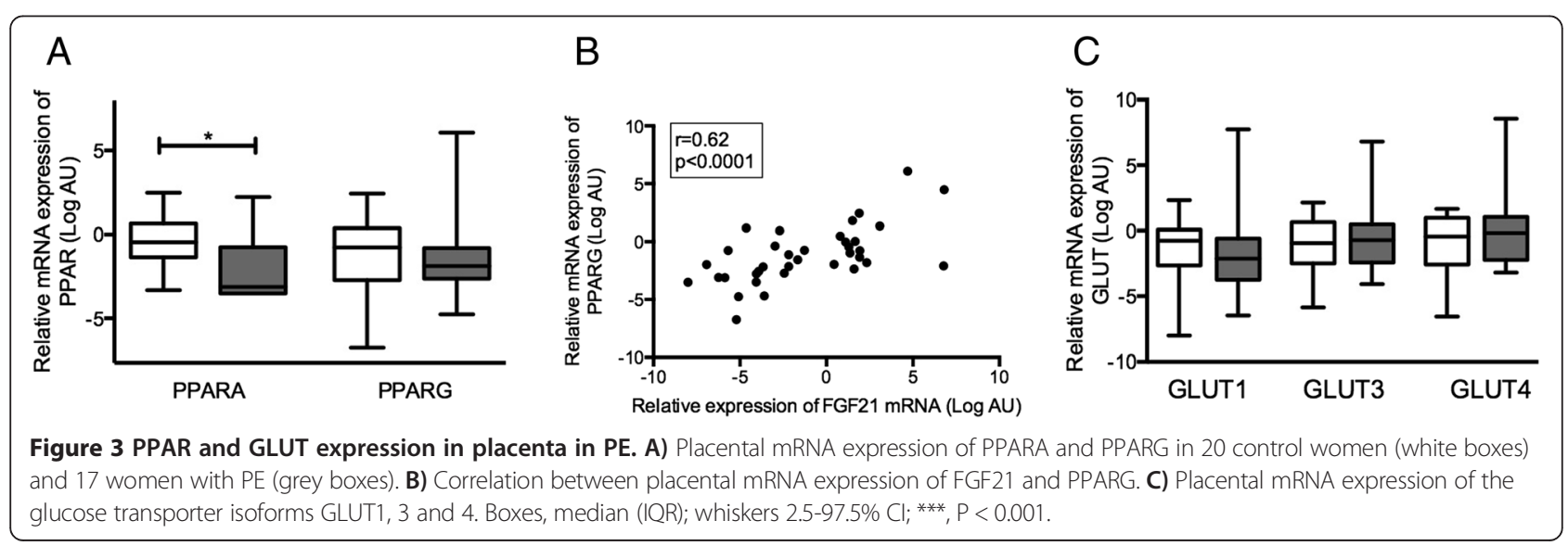


and unaltered PPAR $\gamma$ expression. The serum levels of FGF21 were not different in PE.

\section{Placental FGF21, receptors and cofactors}

Placental FGF21 mRNA and protein expression is highly variable in normal pregnancies as well as in pregnancies affected by late-onset preeclampsia (current study) or gestational diabetes mellitus [14]. In the current study we found no changes in mRNA and protein levels, or localization. The positive correlations between the placental expression of FGF21 and its receptors and cofactor found in the current study could suggest that they may be regulated by common mechanisms and that interindividual variations in the expression of members of the FGF21 pathway in the placenta are common. This may result in small differences in lipid and glucose metabolism in the placenta between women. This could occur despite unchanged expression of glucose transporters: it has been argued that placental glucose transport is not limited by transport capacity but rather by blood flow [19].

\section{Placental PPARs}

In the current study, PPAR $\alpha$ mRNA levels were significantly decreased in PE. In contrast, we recently reported that in placentae from women with GDM, there is an increase in PPAR $\alpha$ [14]. PPAR $\gamma$ was not significantly decreased in the placentae of women with late-onset PE. Previous studies have variably reported an increase in PPAR $\alpha$ and decrease of PPAR $\gamma$ expression in PE [20] or no change $[21,22]$. These differences may be due to differences in disease severity, gestational age, BMI and ethnicity. PE combined with intrauterine growth restriction, which suggests more severe pathology, is associated with larger differences in PPAR expression [21]. In contrast to our previous results in placentae from women with or without gestational diabetes [14], PPAR $\alpha$ expression is not correlated to FGF21 expression. This could indicate that the regulation of FGF21 mRNA expression is altered in PE.

\section{GLUT in placenta}

The placenta expresses the glucose transporters GLUT1, 3 and 4 [23-25]. GLUT expression in PE has not been studied in detail previously. Placental expression of GLUT3 is increased in idiopathic intrauterine growth restriction [26]. In gestational diabetes mellitus, an increase in the placental expression of GLUT3 and 4 has been observed [14]. GLUT3 in intrauterine growth restriction was colocalized with the hypoxic transcription factor HIF-1 $\alpha$ [26] whereas FGF21 has been reported to induce GLUT1 expression in adipocytes [27]. HIF-1 $\alpha$ expression is increased in preeclampsia $[28,26]$. It may therefore be that the regulation of glucose transporters is regulated differently in gestational diabetes mellitus and the hypoxic conditions of PE and intrauterine growth restriction.

\section{Serum FGF21}

Serum FGF21 levels are highly variable both in pregnancy [13] and outside of pregnancy [29-31]. Maternal serum FGF21 levels have previously been reported to be increased in PE [13]. In our study, we did not observe a significant change in maternal FGF21 levels. Overall, the serum concentration of FGF21 in our samples was similar to recent studies $[13,32,10]$. The lack of an elevation in FGF21 in the maternal serum of women with PE in our study may be due to differences in the characteristics of the study participants such as BMI, insulin resistance, gestation at blood sampling and parity [31]. Most of the women included in the current study were not obese, and FGF21 serum levels did not correlate with pre-pregnancy BMI. The higher glucose screen results indicate the higher level of insulin resistance in the women who went on to develop PE. This is consistent with previous studies showing a positive association between PE and insulin resistance (reviewed in [33]). Circulating FGF21 in pregnancy has previously been positively correlated with fasting insulin, triglycerides and leptin levels but negatively with LDL cholesterol in univariate analyses [13]. In multivariate analyses, the associations with LDL cholesterol and triglyceride remained even after adjustment for PE [13]. Additionally, the women with PE in our cohort all had late-onset PE whereas in the previous study, the participants likely suffered from early-onset PE since they delivered at a mean of 30 weeks gestation. In obesity, circulating FGF21 is increased [34]. The large inter-individual variability in FGF21 levels may also contribute especially with the relatively limited sample sizes of the studies to date.

FGF21 has been independently positively associated with hypertension in a community sample [29]. In our study, circulating maternal FGF21 was positively correlated with systolic blood pressure at enrolment and there was a trend for a correlation with diastolic blood pressure. This is a cross-sectional study and no causality can be inferred from our results. However, FGF21 levels have previously been associated with activity of the reninangiotensin system in patients with end-stage renal disease on dialysis [35]. FGF21 was negatively correlated with residual renal function. Treatment with angiotensin receptor blockers reduced serum FGF21 concentrations independent of the inflammatory and insulin resistantstate. The FGF21 levels in this study were positively correlated to the level of insulin resistance in these dialysis patients independent of residual renal function, indicating that the regulation of FGF21 is complex. 
A recent study showed the presence of low levels of FGF21 in the cord blood of $93 \%$ of their cohort of term and preterm infants [36]. The reported levels were at the threshold for detection for our assay and there was again a wide interindividual spread in the levels of FGF21. There was no difference in serum FGF21 in cord blood between term and preterm infants suggesting that FGF21 does not affect prenatal growth. This study reported a negative correlation between FGF21 levels and growth in length but not weight over the first six months of life [36], indicating that postnatally FGF21 may be a negative regulator of growth.

\section{Conclusions}

In summary, late-onset preeclampsia is not associated with major changes to the expression of FGF21 or its receptors. The associations of FGF21 with the transcriptional regulator PPAR $\alpha$ observed in placentas from women with gestational diabetes mellitus was not observed in placentas from women with late-onset preeclampsia. Gene expression levels of glucose transporters, which are targets of FGF21 signaling, were not affected by preeclampsia.

\section{Additional files}

Additional file 1: Table S1. Primer sequences.

Additional file 2: Figure S1. FGF21 localization in decidual cells.

\section{Abbreviations}

FGF21: Fibroblast growth factor 21; GLUT: Glucose transporter; PE: Preeclampsia.

\section{Competing interests}

The authors declare that they have no competing interests.

\begin{abstract}
Authors' contributions
MDN conceived of the study, carried out experiments, analyzed data and wrote the manuscript. KSR and MHK carried out experiments, analyzed data and edited the manuscript. HDM interpreted data and edited the manuscript. LKC collected samples, interpreted data and edited the manuscript. HLB conceived of the study, carried out experiments, analyzed data and edited the manuscript. All authors read and approved the final version of the manuscript.
\end{abstract}

\section{Acknowledgements \\ The authors thank the research midwifes, obstetrics and midwifery staff of the Royal Brisbane and Women's Hospital for their help with sample collection. MDN was supported by a Royal Brisbane and Women's Hospital Scholarship. Funding was provided by the National Health and Medical Research Council (NHMRC; grant 569693) and an ADIPS Novo Nordisk Research grant.}

\section{Author details}

${ }^{1}$ School of Medicine, The University of Queensland, Butterfield Street, Herston 4029, QLD, Australia. ${ }^{2}$ The University of Queensland Centre for Clinical Research, The University of Queensland, Herston, QLD, Australia. ${ }^{3}$ Obstetric Medicine, Royal Brisbane and Women's Hospital, Herston, QLD, Australia. ${ }^{4}$ Mater Health Services, South Brisbane, QLD, Australia.

Received: 9 October 2014 Accepted: 9 February 2015

Published online: 08 March 2015

\section{References}

1. Eiland E, Nzerue C, Faulkner M. Preeclampsia 2012. J Pregnancy. 2012;2012:586578. doi:10.1155/2012/586578.

2. Bellamy L, Casas J-P, Hingorani AD, Williams DJ. Pre-eclampsia and risk of cardiovascular disease and cancer in later life: systematic review and meta-analysis. BMJ. 2007;335(7627):974.

3. Nerenberg K, Daskalopoulou SS, Dasgupta K. Gestational diabetes and hypertensive disorders of pregnancy as vascular risk signals: an overview and grading of the evidence. Can J Cardiol. 2014;30(7):765-773.

4. Sibai B, Dekker G, Kupferminc M. Pre-eclampsia. Lancet. 2005;365(9461):785-799.

5. Kharitonenkov A, Shiyanova TL, Koester A, Ford AM, Micanovic R, Galbreath EJ, et al. FGF-21 as a novel metabolic regulator. J Clin Invest. 2005;115(6):1627-35. doi:10.1172/JCI23606.

6. Wente W, Efanov AM, Brenner M, Kharitonenkov A, Koster A, Sandusky GE, et al. Fibroblast growth factor-21 improves pancreatic beta-cell function and survival by activation of extracellular signal-regulated kinase 1/2 and Akt signaling pathways. Diabetes. 2006;55(9):2470-8. doi:10.2337/db05-1435.

7. De Sousa-Coelho AL, Relat J, Hondares E, Perez-Marti A, Ribas F, Villarroya F, et al. FGF21 mediates the lipid metabolism response to amino acid starvation. J Lipid Res. 2013;54(7):1786.

8. Ge X, Chen C, Hui X, Wang Y, Lam KS, Xu A. Fibroblast growth factor 21 induces glucose transporter-1 expression through activation of the serum response factor/Ets-like protein-1 in adipocytes. J Biol Chem. 2011;286(40):34533-34541. doi:10.1074/jbc.M111.248591.

9. Mraz M, Bartlova M, Lacinova Z, Michalsky D, Kasalicky M, Haluzikova D, et al. Serum concentrations and tissue expression of a novel endocrine regulator fibroblast growth factor-21 in patients with type 2 diabetes and obesity. Clin Endocrinol (Oxf). 2009;71(3):369-375. doi:10.1111/j.1365-2265.2008.03502.x.

10. Li S-M, Wang W-F, Zhou L-H, Ma L, An Y, Xu W-J et al. Fibroblast growth factor 21 expressions in white blood cells and sera of patients with gestational diabetes mellitus during gestation and postpartum. Endocrine. 2014:1-9. doi:10.1007/s12020-014-0309-8.

11. Ribas F, Villarroya J, Hondares E, Giralt M, Villarroya F. FGF21 expression and release in muscle cells: involvement of MyoD and regulation by mitochondria-driven signalling. Biochem J. 2014;463(2):191-199. doi:10.1042/ BJ20140403.

12. Tan BK, Sivakumar K, Bari MF, Vatish M, Randeva HS. Lower cerebrospinal fluid/plasma fibroblast growth factor 21 (FGF21) ratios and placental FGF21 production in gestational diabetes. PLoS One. 2013;8(6):e65254. doi:10.1371/journal.pone.0065254

13. Stepan H, Kley K, Hindricks J, Kralisch S, Jank A, Schaarschmidt W, et al. Serum levels of the adipokine fibroblast growth factor-21 are increased in preeclampsia. Cytokine+. 2013;62(2):322-6. doi:10.1016/j.cyto.2013.02.019.

14. Dekker Nitert M, Barrett HL, Kubala MH, Scholz Romero K, Denny KJ, Woodruff TM, et al. Increased placental expression of fibroblast growth factor 21 in gestational diabetes mellitus. J Clin Endocrinol Metab. 2014;99(4):E591-8. doi:10.1210/jc.2013-2581.

15. Yang C, Jin C, Li X, Wang F, McKeehan WL, Luo Y. Differential Specificity of Endocrine FGF19 and FGF21 to FGFR1 and FGFR4 in Complex with KLB. PLoS One. 2012;7(3):e33870. doi:10.1371/journal.pone.0033870.

16. Muise ES, Azzolina B, Kuo DW, El-Sherbeini M, Tan Y, Yuan X, et al. Adipose fibroblast growth factor 21 is up-regulated by peroxisome proliferator-activated receptor gamma and altered metabolic states. Mol Pharmacol. 2008;74(2):403-412. doi:10.1124/mol.108.044826.

17. Hondares E, Rosell M, Gonzalez FJ, Giralt M, Iglesias R, Villarroya F. Hepatic FGF21 expression is induced at birth via PPARalpha in response to milk intake and contributes to thermogenic activation of neonatal brown fat. Cell Metab. 2010;11(3):206-212. doi:10.1016/j.cmet.2010.02.001.

18. Lowe SA, Brown MA, Dekker GA, Gatt S, McLintock CK, McMahon LP, et al. SOMANZ Guidelines for the management of hypertensive disorders of pregnancy 2008. 2008. https://www.somanz.org/pdfs/somanz_guidelines_2008.pdf.

19. Desoye G, Gauster M, Wadsack C. Placental transport in pregnancy pathologies. Am J Clin Nutr. 2011. doi:10.3945/ajcn.110.000851.

20. He P, Chen Z, Sun Q, Li Y, Gu H, Ni X. Reduced expression of 11 betahydroxysteroid dehydrogenase type 2 in preeclamptic placentas is associated with decreased PPARgamma but increased PPARalpha expression. Endocrinology. 2013;155(1):299-309. doi:10.1210/en.2013-1350.

21. Holdsworth-Carson SJ, Lim R, Mitton A, Whitehead C, Rice GE, Permezel M, et al. Peroxisome proliferator-activated receptors are altered in pathologies of the human placenta: gestational diabetes mellitus, intrauterine growth 
restriction and preeclampsia. Placenta. 2010;31(3):222-9. doi:10.1016/ j.placenta.2009.12.009.

22. Rodie VA, Young A, Jordan F, Sattar N, Greer IA, Freeman DJ. Human placental peroxisome proliferator-activated receptor delta and gamma expression in healthy pregnancy and in preeclampsia and intrauterine growth restriction. J Soc Gynecol Investig. 2005;12(5):320-329. doi:10.1016/j.jsgi.2005.03.004.

23. Hay Jr WW. Placental-fetal glucose exchange and fetal glucose metabolism. Trans Am Clin Climatol Assoc. 2006;117:321-39. discussion 39-40.

24. Xing AY, Challier JC, Lepercq J, Caüzac M, Charron MJ, Girard J, et al. Unexpected expression of glucose transporter 4 in villous stromal cells of human placenta. J Clin Endocrinol Metab. 1998;83(11):4097-4101.

25. Hauguel-de Mouzon S, Challier JC, Kacemi A, Cauzac M, Malek A, Girard J. The GLUT3 glucose transporter isoform is differentially expressed within human placental cell types. J Clin Endocrinol Metab. 1997;82(8):2689-2694. doi:10.1210/jcem.82.8.4147.

26. Janzen C, Lei MYY, Cho J, Sullivan P, Shin BC, Devaskar SU. Placental glucose transporter 3 (GLUT3) is up-regulated in human pregnancies complicated by late-onset intrauterine growth restriction. Placenta. 2013;34(11):1072-1078. doi:10.1016/j.placenta.2013.08.010.

27. Li K, Li L, Yang M, Liu H, Boden G, Yang G. The effects of fibroblast growth factor-21 knockdown and over-expression on its signaling pathway and glucose-lipid metabolism in vitro. Mol Cell Endocrinol. 2012;348(1):21-26. doi:10.1016/j.mce.2011.07.026

28. Rajakumar A, Brandon HM, Daftary A, Ness R, Conrad KP. Evidence for the functional activity of hypoxia-inducible transcription factors overexpressed in preeclamptic placentae. Placenta. 2004;25(10):763-769. doi:10.1016/j.placenta.2004.02.011.

29. Semba RD, Crasto C, Strait J, Sun K, Schaumberg DA, Ferrucci L. Elevated serum fibroblast growth factor 21 is associated with hypertension in community-dwelling adults. J Hum Hypertens. 2013;27(6):397-399. doi:10.1038/jhh.2012.52.

30. Yang SJ, Hong HC, Choi HY, Yoo HJ, Cho GJ, Hwang TG, et al. Effects of a three-month combined exercise programme on fibroblast growth factor 21 and fetuin-A levels and arterial stiffness in obese women. Clin Endocrinol (Oxf). 2011;75(4):464-9. doi:10.1111/j.1365-2265.2011.04078.x.

31. Gallego-Escuredo JM, Gomez-Ambrosi J, Catalan V, Domingo P, Giralt M, Fruhbeck G, et al. Opposite alterations in FGF21 and FGF19 levels and disturbed expression of the receptor machinery for endocrine FGFs in obese patients. Int J Obes. 2015;39(1):121-9. doi:10.1038/ijo.2014.76.

32. Stein S, Stepan H, Kratzsch J, Verlohren M, Verlohren H-J, Drynda K, et al. Serum fibroblast growth factor 21 levels in gestational diabetes mellitus in relation to insulin resistance and dyslipidemia. Metabolism. 2010;59(1):33-37. doi:10.1016/j.metabol.2009.07.003.

33. Scioscia M, Gumaa K, Rademacher TW. The link between insulin resistance and preeclampsia: new perspectives. J Reprod Immunol. 2009;82(2):100-105. doi:10.1016/j.ji.2009.04.009.

34. Zhang X, Yeung DC, Karpisek M, Stejskal D, Zhou ZG, Liu F, et al. Serum FGF21 levels are increased in obesity and are independently associated with the metabolic syndrome in humans. Diabetes. 2008:57(5):1246-1253. doi:10.2337/db07-1476.

35. Han SH, Choi SH, Cho BJ, Lee Y, Lim S, Park YJ, et al. Serum fibroblast growth factor-21 concentration is associated with residual renal function and insulin resistance in end-stage renal disease patients receiving long-term peritoneal dialysis. Metabolism. 2010;59(11):1656-1662. doi:10.1016/j.metabol.2010.03.018.

36. Mericq V, De Luca F, Hernandez Ml, Peña V, Rossel K, Garcia M, et al. Serum fibroblast growth factor 21 levels are inversely associated with growth rates in infancy. Horm Res Paediatr. 2014;82(5):324-331.

\section{Submit your next manuscript to BioMed Central and take full advantage of:}

- Convenient online submission

- Thorough peer review

- No space constraints or color figure charges

- Immediate publication on acceptance

- Inclusion in PubMed, CAS, Scopus and Google Scholar

- Research which is freely available for redistribution

Submit your manuscript at www.biomedcentral.com/submit 